\title{
Femoral Vein
}

National Cancer Institute

\section{Source}

National Cancer Institute. Femoral Vein. NCI Thesaurus. Code C12716.

A vein that starts within the inguinal region and extends to the lower extremities. 